14

\title{
Сверхтермостойкие полимерные нанокомпозиты на основе гетероциклических сеток: структура и свойства
}

\author{
(C) В.А. Берштейн ${ }^{1}$, А.М. Файнлейб ${ }^{2}$, П.Н. Якушев ${ }^{1}$, Д.А. Кириленко ${ }^{1}$, О.Г. Мельничук ${ }^{2,3}$ \\ ${ }^{1}$ Физико-технический институт им. А.Ф. Иофрфе РАН, \\ Санкт-Петербург, Россия \\ ${ }^{2}$ Институт химии высокомолекулярных соединений НАНУ, \\ Киев, Украина \\ ${ }^{3}$ Национальный университет „Киево-Могилянская академия“, \\ Киев, Украина \\ E-mail: vbersht.polmater@mail.ioffe.ru
}

Поступила в Редакцию 19 марта 2019 г.

В окончательной редакции 19 марта 2019 г.

Принята к публикации 19 марта 2019 г.

\begin{abstract}
Исследованы нанокомпозиты на основе гетероциклической полимерной сетки, полученной из бисфталонитрила, и различного содержания (от 0.03 до $5 \mathrm{wt} . \%$ ) модифицированных силикатных нанослоев монтмориллонита (ММТ). Наноструктура, термические, релаксационные и упругие свойства композитов охарактеризованы методами просвечивающей электронной микроскопии (TEM), энергодисперсионной рентгеновской спектроскопии (EDXS), динамического механического анализа (DMA) и термогравиметрического анализа (TGA). DMA- и TGA-измерения выполнялись в средах воздуха и азота в диапазоне температур от $20^{\circ}$ до $600-900^{\circ} \mathrm{C}$. В зависимости от содержания ММТ, наблюдалась различная степень его эксфолиации в матрице с образованием единичных нанослоев, тонких и „толстых“ пачек нанослоев ММТ. Показаны сильные эффекты торможения динамики матрицы наночастицами („,constraining dynamics“) и резко выраженной динамической гетерогенности в переходе стеклования. Обнаружены возможности полного подавления последнего и сохранения неизменными упругих характеристик композитов при температурах от 20 до $600^{\circ} \mathrm{C}$. Исследованные нанокомпозиты проявляют уникально высокие для полимеров термические свойства. Достигаются температура стеклования $570^{\circ} \mathrm{C}$ и удовлетворительная термостабильность, с сохранением целостности материала до $\sim 500^{\circ} \mathrm{C}$ в среде воздуха и до $\sim 900^{\circ} \mathrm{C}$ в среде азота.
\end{abstract}

Ключевые слова: полимерные нанокомпозиты, термостабильные материалы, гетероциклические сетки, монтмориллонит, наноструктура.

DOI: $10.21883 /$ FTT.2019.08.47986.428

\section{1. Введение}

С развитием техники возрастают интерес и требования к легким высокотермостойким полимерным материалам, способным эксплуатироваться (иногда кратковременно) в экстремальных условиях (при температурах до $300-400^{\circ} \mathrm{C}$ и выше), в частности в авиации, в космоce, в ракетной технике, в микроэлектронике, в „горячих зонах“ различных конструкций. Основное направление в этом отношении - это создание нанокомпозитов на основе комбинации термостойких матриц и неорганических наночастиц.

Наибольшей термостабильностью среди полимеров обладают гетероциклические полимеры (полиимиды, полибензимидазолы, полибензоксазины и др.), используемые на практике в основном до $200-250^{\circ} \mathrm{C}$. Особый интерес в качестве матриц композитов представляют густосшитые гетероциклические сетки, получаемые полимеризацией нитрил $(-\mathrm{C} \equiv \mathrm{N})$-содержащих соединений, в частности, на основе дициановых эфиров, способные к работе при температурах до $\sim 300^{\circ} \mathrm{C}[1,2]$. Однако, в последние годы ведущее положение в этой области занял класс густосшитых гетероциклических полимеров, синтезируемых из бисфталонитрилов и открывающих перспективу использования нанокомпозитов при температурах $300-400^{\circ} \mathrm{C}$ и выше [3].

Первые работы по синтезу фталонитрильных сетчатых полимеров были опубликованы Келлером с сотрудниками [4-6]. Недавние публикации по фталонитрильным нанокомпозитам (с наночастицами графена [7], нитрида кремния [8], керамики [9], ZnO [10], кремнекислородных частиц POSS [11]), показали существенные эффекты усиления термических и механических свойств матрицы наночастицами и превосходство этих нанокомпозитов над всеми другими термостабильными полимерными материалами. Однако, фундаментальные физические исследования этих композитов почти полностью отсутствуют.

Среди наночастиц, используемых для получения полимерных нанокомпозитов, особое место занимают силикатные 2-D нанослои толщиной около $1 \mathrm{~nm}$, получаемые расщеплением („эксфолиацией“) блоков минерала монтмориллонита (ММТ) в матрице. Этому способствуют большое соотношение геометрических размеров (high aspect ratio) 2-D нанослоев, их хорошие свойства, a также доступность в природе и низкая стоимость ММТ. 


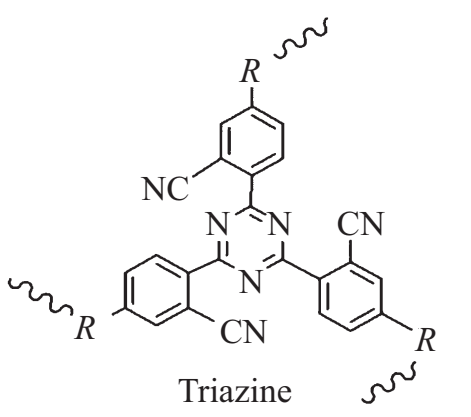<smiles>CC(C)(C)[C@H](N)CCN</smiles>

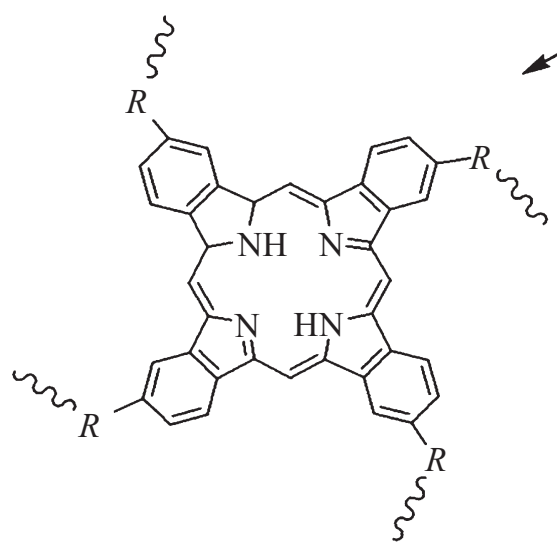

Phthalocyanine<smiles>CC(C)C</smiles><smiles>C#COc1ccc(C(C)(C)c2ccc(OC)cc2)cc1</smiles><smiles>CCCNC1=NC(=N)c2ccc([Tl])cc21</smiles>

Isoindoline

Рис. 1. Химические формулы исходного мономера $\mathrm{BAPhN}$ и гетероциклов - узлов образующейся полимерной сетки матрицы, а также схема гибридизации (прививки) матрицы с функционализированной наночастицей ММТ.

Недавно [12] нами было выполнено комплексное физическое исследование структуры и свойств для серии фталонитрильных нанокомпозитов с $0.5 \%$ кремнийсодержащих наночастиц различной природы (MMT, POSS) и поверхностной модификации. В настоящей работе исследовали наноструктуру, термические, релаксационные и упругие свойств фталонитрильных нанокомпозитов с различным содержанием органомодифицированных нанослоев ММТ (,амино-ММТ“) - от 0.03 до 5 wt.\%.

\section{2. Объекты и методы исследования}

Исследуемые нанокомпозиты были синтезированы из мономера 2,2-бис[4-(3,4-дицианофенокси)фенил] пропана (бисфталонитрил бисфенола $\mathrm{A}, \mathrm{BAPhN})$, производства Завода химических реактивов в г.Шостка (Украина), и наночастиц органо-модифицированного монтмориллонита (ММТ). Последний содержал $70-75 \mathrm{wt} . \%$ чистого ММТ и 25-30 wt.\% октадециламина и был получен от Nanocor Inc. (США) под маркой Nanomer ${ }^{\circledR}$ I.30E. Смеси BAPhN с MMT отверждали ступенчатым нагреванием в течение $8 \mathrm{~h}$ при $260^{\circ}, 8 \mathrm{~h}$ при $280^{\circ}$ и $10 \mathrm{~h}$ при $300^{\circ} \mathrm{C}$. Подобным же образом синтезировали индивидуальный полимер (BAPhN матрица). Композиты, отвержденные при $T \leq 300^{\circ} \mathrm{C}$, имели степень полимеризации $(\mathrm{CП})$ групп $-\mathrm{C} \equiv \mathrm{N}$ матрицы равную
83-89\%; неполнота полимеризации была обусловлена подавленной подвижностью и стерическими затруднениями для завершения этой реакции в полимерной сетке [12]. Ввиду этого проводили также доотверждение образцов нагреванием до $430^{\circ} \mathrm{C}$ со скоростью $3 \mathrm{grad} / \mathrm{min}$ непосредственно в установке DMA (см. ниже). Предельно достижимая при этом СП равнялась 95\% [12]. Образцами служили пленки толщиной около $0.5 \mathrm{~mm}$. Как показано спектроскопическими экспериментами в средней и дальней ИК области [12], полимеризованная матрица представляет собой густосшитую аморфную полимерную сетку сложного строения, включающую три вида гетероциклов - триазиновый, изоиндолиновый и фталоцианиновый. При этом основной вклад в молекулярное строение матрицы вносят макроциклы фталоцианина. „Встраивание“ функционализированных наночастиц ММТ в матрицу обеспечивается высокой реакционной способностью групп $-\mathrm{C} \equiv \mathrm{N}$ мономера относительно аминных групп наночастиц. На рис. 1 показаны химические формулы мономера BAPhN и образующихся при полимеризации гетероциклов (узлов сетки), а также приведен пример гибридизации (прививки) матрицы с функционализированной наночастицей ММТ.

Наноструктуру композитов исследовали методами трансмиссионной электронной микроскопии (ТЕМ) и знергодисперсионной рентгеновской спектроскопии 

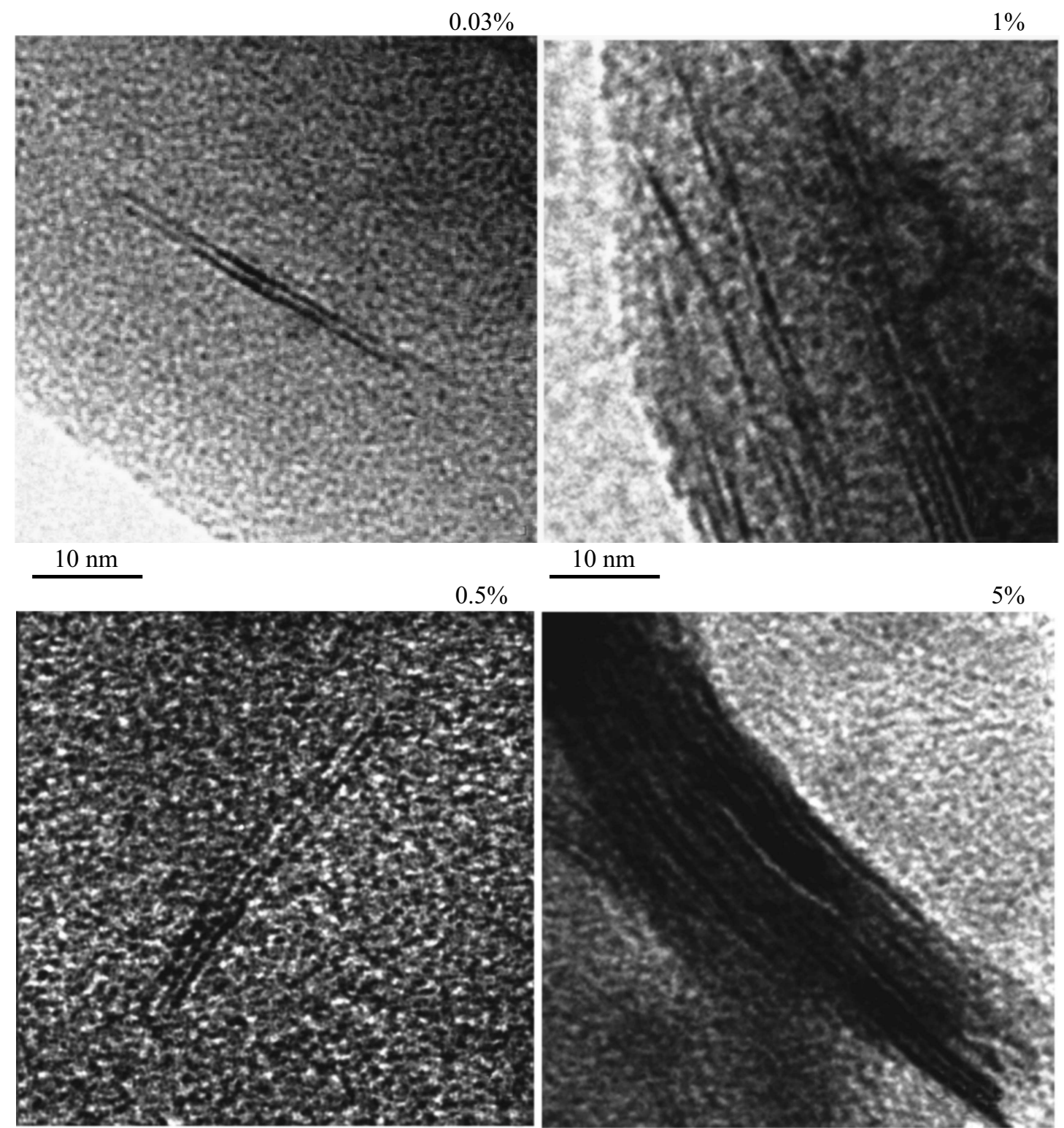

$10 \mathrm{~nm}$



$10 \mathrm{~nm}$

Pис. 2. ТЕМ микрофото BAPhN/MМТ нанокомпозитов с $0.03,0.5,1$ и 5 wt.\% MMT.

(EDXS). Для этого использовались микроскоп Jeol JEM-2100F (ускоряющее напряжение $200 \mathrm{kV}$, разрешение $0.19 \mathrm{~nm})$ и энергодисперсионный $X$-ray спектрометр INCA (Oxford Instruments). EDX спектры получали при фокусировании электронного пучка на площадки диаметром $2 \mathrm{~nm}$. С помощью ТЕМ оценивалась степень расщепления (,эксфолиации“) блоков нанослоев MMT в композитах. Методом EDXS определяли элементный состав в нанообъемах образцов, в частности прямо подтверждали присутствие единичных нанослоев ММТ (элементов $\mathrm{Si}, \mathrm{Al}$ и $\mathrm{Mg}$ ). Ввиду хрупкости исследуемых материалов, использовалась специальная методика приготовления образцов для ТЕМ, описанная в $[12,13]$.

Релаксационные, упругие и термические свойства нанокомпозитов оценивались методами динамического ме- ханического анализа (DMA) и термогравиметрического анализа (TGA). DMA эксперименты выполнялись на спектрометре DMS 6100 (Seiko Instruments, Japan) при растяжении (частота $1 \mathrm{~Hz}$ ) в температурном диапазоне от $20^{\circ}$ до $570^{\circ} \mathrm{C}$, при скорости нагревания $3 \mathrm{grad} / \mathrm{min}$, на образцах с размером рабочей части $20 \times 5 \times 0.5 \mathrm{~mm}^{3}$. Определяли температурные зависимости динамического модуля $E^{\prime}$, модуля механических потерь $E^{\prime \prime}$ и $\tan \delta=E^{\prime \prime} / E^{\prime}$. Температура стеклования $T_{g}$ оценивалась по максимумам пиков $\tan \delta$. TGA выполнялся на прибоpe TGA Q50 (TA Instruments, USA) в температурном диапазоне от $20^{\circ}$ до $900^{\circ} \mathrm{C}$, при скорости нагревания $20 \mathrm{grad} / \mathrm{min}$. Масса образцов равнялась $10-20 \mathrm{mg}$. DMA и TGA опыты выполнялись в среде воздуха и в инертной среде (в потоке азота). 


\section{3. Результаты и их обсуждение}

\section{1. Наноструктура композитов}

На рис. 2 представлены характерные ТЕМ фото нанокомпозитов, содержащих $0.03,0.5,1$ и $5 \mathrm{wt} . \%$ MMT. Видно, что эти нанокомпозиты проявляют сильно различающиеся характеристики расслоения (эксфолиации) ММТ в аморфной фталонитрильной матрице. Наибольшая степень эксфолиации, вплоть до единичных нанослоев ММТ толщиной $\sim 1 \mathrm{~nm}$ или двухслойных образований наблюдается при $0.03 \%$ ММТ. В композитах с $0.5 \%$ ММТ эксфолиация приводит к возникновению преимущественно трех-четырех-слойных пачек ММТ. Наиболее интересная картина эксфолиации ММТ в матрице наблюдается для нанокомпозита с 1\% ММТ. В этом случае можно видеть на $100 \mathrm{~nm}$ фото одновременно совершенно разные степени эксфолиации ММТ: единичные нанослои, двухслойные образования и пятидесяти-слойные пачки ММТ. Степень эксфолиации резко


Рис. 3. Характерные EDX спектры BAPhN/MMT нанокомпозитов, полученные с площадок диаметром $2 \mathrm{~nm}$ при фокусировании электронного пучка на матрице, единичным нанослое MМТ и на пачке нанослоев ММТ. Сигнал от $\mathrm{Cu}$ не относится к образцу (см. текст). понижалась с ростом содержания ММТ до 2 и особенно до $5 \%$ в нанокомпозитах. В первом случае тонкие ММТ пачки превалировали в нанокомпозите, а во втором наблюдалось образование пачек ММТ толщиной около 5 и $20-30 \mathrm{~nm}$ (рис. 2).

На рис. 3 приводятся типичные EDX спектры, полученные при фокусировании электронного пучка на площадку диаметром около $2 \mathrm{~nm}$ разных участков нанокомпозита - матрицы, единичного нанослоя ММТ и пачки нанослоев ММТ. Эти спектры, включающие сигналы от основных элементов $\mathrm{MMT}(\mathrm{Si}, \mathrm{Al}, \mathrm{Mg})$, полностью согласуются с данными ТЕМ, например, подтверждают, что темные линии на ТЕМ фото отвечают, действительно, нанослою ММТ толщиной около $1 \mathrm{~nm}$. При анализе спектров рис. 3 следует отметить три момента. Вопервых, ширина электронного пучка несколько превышает толщину единичного нанослоя ММТ и поэтому его EDX спектр неизбежно содержит также сигнал от элементов полимерной матрицы $(\mathrm{C}, \mathrm{O})$. Наиболее четкое изображение нанослоя в ТЕМ и соответственно наиболее сильный сигнал основных элементов ММТ в EDX спектре наблюдаются при ориентации нанослоя параллельно электронному пучку. Естественно, пачки нанослоев ММТ обеспечивают более сильные сигналы элементов MMT в EDX спектрах. Во-вторых, можно видеть небольшой сигнал элементов MMT в EDX спектре матрицы. Это объясняется тем, что электронный пучок может пересекать под тупым углом нанослои MМТ, неразличимые методом ТЕМ. И, в-третьих, наблюдаемый всегда пик меди в EDX спектрах не имеет отношения к исследуемым нанокомпозитам: этот сигнал возникает от медной сетки - держателя образца.

\section{2. Динамический механический анализ нанокомпозитов}

Результаты, полученные методом DMA, представлены на рис. 4 и 5 и в таблице. Рис. 4 представляет характерные $\tan \delta(T)$ и $E^{\prime}(T)$ зависимости, полученные для доотвержденных пленок чистой $\mathrm{BAPhN}$ матрицы и трех нанокомпозитов с $0.03,1$ и $5 \%$ ММТ. В таблице приводятся значения температур стеклования $T_{g}$, полученные для доотвержденных образцов всех исследованных композитов как температуры максимумов пиков на кривых $\tan \delta(T)$.

Для отвержденных образцов, т.е. при первом сканировании до $430^{\circ} \mathrm{C}$, DMA дает значения $T_{g} \approx 380-390^{\circ} \mathrm{C}$ как для чистой матрицы, так и для нанокомпозитов; примером такого релаксационного спектра является кривая 1 на рис. 5. Следовательно, в этом случае влияние нанослоев ММТ на динамику матрицы оказывается пренебрежимо малым. Для доотвержденных образцов, т.е. после повышения степени полимеризации матрицы от 89 до 95\% [12], релаксационные спектры образцов с густосшитой гетероциклической матрицей кардинально изменялись. В целом эти нанокомпозиты характеризуются резким повышением $T_{g}$ (в пределе почти на $200^{\circ}$ ). 



Рис. 4. Данные DMA (1 Hz): зависимости $\tan \delta(T)(a)$ и $E^{\prime}(T)(b)$, полученные для доотвержденных образцов чистой матрицы $\mathrm{BAPhN}$ (1) и для BAPhN/MMT нанокомпозитов с 0.03 (2), 1 (3) и 5 wt.\% MMT (4).



Рис. 5. Данные DMA (1 Hz): зависимости $\tan \delta(T)(1,2)$ и $E^{\prime}(T)(3,4)$, полученные для отвержденного образца нанокомпозита BAPhN/MMT $(0.5 \%)$ при первом сканировании в среде воздуха $(1,3)$ и при повторном сканировании в среде азота после нагревания в этой инертной среде до $570^{\circ} \mathrm{C}(2,4)$.

Это указывает на сильный эффект подавления наночастицами динамики полимерной матрицы. Кроме того, наблюдается весьма низкий уровень механических потерь, в основном не более $0.02-0.05$ во всем исследованном диапазоне температур - от $20^{\circ}$ до $\sim 600^{\circ} \mathrm{C}$. В целом основная релаксационная область перехода стеклования простирается от $\sim 400^{\circ}$ до $570^{\circ} \mathrm{C}$. Кроме того, в спектрах отчетливо регистрируются широкие перекрывающиеся области релаксаций при температурах 50-100 и $200-250^{\circ} \mathrm{C}$.

Рис. 4 показывает единичный пик стеклования с максимумом $T_{g}=446^{\circ} \mathrm{C}$ для индивидуальной матрицы. Абсолютно иные релаксационные спектры наблюдаются для нанокомпозитов с разным содержанием ММТ. Их общая черта - значительный рост $T_{g}$, вплоть до $570^{\circ} \mathrm{C}$, вследствие частичного подавления молекулярной динамики матрицы наночастицами („constrained dynamics effect", см. например обзорные статьи $[14,15])$ и несходные, усложненные спектральные контуры, имеющие в области перехода стеклования в основном дублетную структуру или три-четыре перекрывающихся пика (таблица и рис. 4). Последнее указывает на возникновение в переходах стеклования нанокомпозитов различной и резко выраженной динамической гетерогенности, которая объясняется присутствием в матрице композита нанообъемов с относительно слабым влиянием нанослоев MМТ $\left(T_{g} \approx 460^{\circ} \mathrm{C}\right)$ и более сильным и различным их воздействием $\left(T_{g} \approx 470,500,520,530-540\right.$ и $570^{\circ} \mathrm{C}$, см. таблицу и рис. 4). Видно, что „встраивание“ в матрицу всего $0.03 \%$ ММТ (единичных нанослоев) приводит к небольшому подавлению динамики (росту $T_{g}$ от 446 до $460^{\circ} \mathrm{C}$ ) в основной части матрицы и возникновению дополнительного узкого пика при $529^{\circ} \mathrm{C}$, характеризующего, по-видимому, $T_{g}$ нанообъемов матрицы на межфазных границах, т.е. примыкающих к индивидуальным нанослоям ММТ. Релаксационная картина усложняется в

Температура стеклования доотвержденных BAPhN/MMT нанокомпозитов (DMA, $1 \mathrm{~Hz}$ )

\begin{tabular}{c|l}
\hline MMT (wt.\%) & \multicolumn{1}{|c}{$T_{g},{ }^{\circ} \mathrm{C}$} \\
\hline 0 & 446 \\
0.03 & 460,529 \\
0.1 & $460,500,540$ \\
0.5 & 455,540 \\
1 & $460,493,520,570$ \\
2 & 460,539 \\
5 & 470
\end{tabular}


случае нанокомпозита с $0.1 \%$ ММТ (три пика в переходе стеклования). При введении 0.5\% ММТ наблюдалась дублетная структура пика стеклования с максимумами при 455 и $540^{\circ} \mathrm{C}$, а у нанокомпозита с $1 \%$ ММТ переход стеклования проявлялся в виде четырех перекрывающихся релаксационных пиков с максимумами при 460 , 493, 520 и $570^{\circ} \mathrm{C}$. Интересно, что в последнем случае динамическая гетерогенность хорошо коррелирует с наноструктурой этого композита: как было показано выше (рис. 2), в пределах $100 \mathrm{~nm}$ ТЕМ фото наблюдалось несколько степеней эксфолиации блоков ММТ (единичные нанослои, двух-, пяти- и десятислойные пачки). Однако, при 2 и особенно 5\% ММТ в композите релаксационная картина в переходе стеклования „упрощается“: в первом случае регистрируется дублет при 460 и $539^{\circ} \mathrm{C}$, а при $5 \%$ ММТ - только пик при $470^{\circ} \mathrm{C}$. Последний результат может быть интерпретирован со структурной точки зрения. В этом случае в композитах присутствуют преимущественно нанообъемы, обогащенные „толстыми“ пачками ММТ, и нанообъемы, относительно свободные от наночастиц (рис. 2), В такой структуре роль межфазных слоев, их влияние на рост $T_{g}$ могут, действительно, оказаться на много меньшими, чем в композитах с малым содержанием ММТ. Уместно отметить, что в недавних работах [16-18] мы обнаружили эффекты особенно большого положительного влияния сверхмалых концентраций кремнийсодержащих наночастиц (в том числе ММТ [16]) на динамику матрицы, полученной из дициановых эфиров бисфенолов, родственной матрице, исследованной в данной работе.

Для доотвержденных образцов нанокомпозитов динамический модуль $E^{\prime} \approx(2.2-2.5) \mathrm{GPa}$ при $30^{\circ} \mathrm{C}$, медленно понижается с ростом температуры и несколько повышается при $T>(430-450)^{\circ} \mathrm{C}$ (максимальная температура при первом сканировании). Затем, однако, величина модуля $E^{\prime}$ вновь уменьшается при температурах $T>500^{\circ} \mathrm{C}$ вследствие термоокислительной деструкции материалов. Отметим, что модуль композита BAPhN/MMT $(0.5 \%)$ при $500^{\circ} \mathrm{C}$ оказался не ниже, чем при $30^{\circ} \mathrm{C}$.

Интерес представляет сравнительный анализ высокотемпературного поведения исследуемых композитов в среде воздуха и в инертной, бескислородной атмосфере (в потоке $N_{2}$ ). Это важно, например, при их возможном использовании в аэрокосмической области (работоспособность при высоких температурах, хотя бы и кратковременная). Рис. 5 представляет данные DMA, полученные при нагревании отвержденного нанокомпозита $\mathrm{BAPhN} / \mathrm{MMT}(0.5 \%)$ на воздухе до $430^{\circ} \mathrm{C}$ и для этого же образца, прогретого предварительно в среде азота от 20 до $570^{\circ} \mathrm{C}$, а затем испытанного также в азоте. Необычный для полимеров, удивительный результат наблюдался в последнем случае: это полное подавление релаксационного спектра, исчезновение перехода стеклования и, особенно, постоянство модуля $E^{\prime} \approx 3 \mathrm{GPa} \mathrm{в}$ температурном диапазоне от 20 до $600^{\circ} \mathrm{C}$.

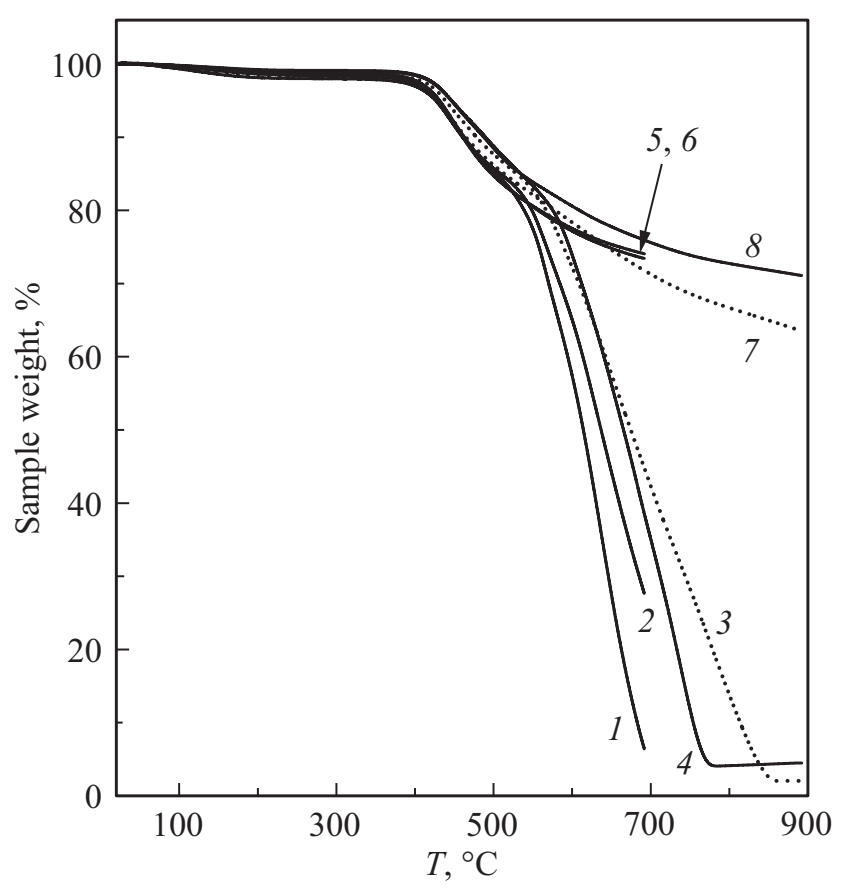

Рис. 6. Данные TGA, полученные в средах воздуха (1-4) и азота $(5-8)$ для доотвержденных образцов чистой BAPhN матрицы $(1,5)$ и BAPhN/MMT нанокомпозитов с $0.5(2,6)$, $2(3,7)$ и $5 \mathrm{wt} . \%$ MMT $(4,8)$.

\section{4. Термогравиметрический анализ нанокомпозитов}

Для чистой $\mathrm{BAPhN}$ матрицы и трех нанокомпозитов с 0.5, 2 и 5\% ММТ методом TGA исследовались термостабильность и термоокислительная деструкция в диапазоне температур от 20 до $700-900^{\circ} \mathrm{C}$. Опыты выполнялись соответственно в инертной среде в потоке азота и в окислительной воздушной атмосфере. Полученные результаты, представленные на рис. 6, указывают на исключительно высокую термостабильность исследуемых полимерных материалов. Видно, что все четыре материала сохраняют стабильность до $\sim 350^{\circ} \mathrm{C}$; потеря массы до $2 \%$ отвечает десорбции влаги. Небольшая деградация начинается с $430^{\circ} \mathrm{C}$, с потерей $5 \%$ массы, причем на этой стадии процесс практически не зависит от характера среды до температуры $\sim 550^{\circ} \mathrm{C}$. При этой температуре удаляется до $20 \%$ массы, хотя полностью сохраняется целостность материалов. На кривых TGA эта температура отвечает „точке бифуркации“ - началу резкого расхождения кривых для сред воздуха и азота. В первом случае идет интенсивный процесс термоокислительной деградации, а в инертной среде дальнейшие деструктивные процессы слабо выражены. $\mathrm{B}$ итоге для чистой матрицы при $\sim 700^{\circ} \mathrm{C}$ остаточная масса равнялась 7\% при нагревании в среде воздуха и $73 \%$ в среде азота (рис. 6).

На рис. 6 представлены также данные TGA, полученные для нанокомпозитов с 0.5, 2 и 5\% ММТ (в случае двух последних композитов измерения проводились до 
$\left.900^{\circ} \mathrm{C}\right)$. При измерениях в инертной среде не отмечалось значительного различия термической стабильности чистой матрицы и нанокомпозитов, хотя все же наибольшей стабильностью обладал нанокомпозит с 5\% ММТ. В этом случае после нагревания до $900^{\circ} \mathrm{C}$ остаточная масса равнялась $71 \%$ и при этом пленки композита также сохраняли целостность. В то же время введение нанослоев ММТ приводило к заметному повышению стабильности материала в среде воздуха. Так, при нагревании до $\sim 700^{\circ} \mathrm{C}$ остаточная масса возрастала от 7\% в случае чистой матрицы до 45\% для композита с $2 \%$ ММТ. Заметим, что опыты выполнялись на пленочных образцах толщиной $0.5 \mathrm{~mm}$. Естественно предположить, что в случае толстых нанокомпозитных деталей влияние окислительной (воздушной) среды может быть менее значительным, чем в наших опытах.

Эффект усиления термической стабильности ММТсодержащих полимерных нанокомпозитов в воздушной среде, наблюдавшийся и ранее (см. обзор [19]), имеет, очевидно, сложную природу. Влияние ММТ обусловлено изменениями кинетики окислительной деструкции вследствие проявления барьерного эффекта, частичного подавления динамики матрицы, ограничения диффузии кислорода и др.

Сверхвысокая термостабильность исследуемых нанокомпозитов в инертной среде азота определяется ведущей ролью исключительно термостойких фталоцианиновых гетероциклов. Действительно, с одной стороны, TGA MMT-содержащих нанокомпозитов с матрицей на основе дициановых эфиров бисфенолов (содержит только триазиновые гетероциклы и бензольные кольца) указывает на весьма интенсивную деградацию их в среде азота уже при $430-500^{\circ} \mathrm{C}$ [16]. С другой стороны, ИК спектроскопический анализ BAPhN/MMT(5\%) нанокомпозита до и после нагревания в среде азота до $900^{\circ} \mathrm{C}$ показал: в результате высокотемпературного пиролиза происходит резкое уменьшение содержания (разрушение) триазиновых и изоиндолиновых гетероциклов и образование из продуктов пиролиза дополнительных наиболее термостойких фталоцианиновых макроциклов

\section{5. Заключение}

1. Синтезирована серия гибридных полимерных нанокомпозитов на основе густосшитых гетероциклических сеток, полученных полимеризацией бисфталонитрила бисфенола А, с введением различных количеств (0.03-5.0 wt.\%) реакционноспособных амино-ММТ нанослоев.

2. Выполнен комплексный анализ методами ТЕМ, EDXS, DMA и TGA их наноструктуры, термических, релаксационных и упругих свойств в температурном диапазоне от 20 до $600-900^{\circ} \mathrm{C}$ в окислительной воздушной атмосфере и в инертной среде азота.

3. В зависимости от содержания ММТ в композите, наблюдались различные степени эксфолиации блоков ММТ в матрице - от единичных нанослоев толщиной около $1 \mathrm{~nm}$ до тонких и „толстых“ пачек таких нанослоев.

4. Прослежена взаимосвязь между наноструктурой и свойствами нанокомпозитов. Обнаружены сильные эффекты торможения динамики матрицы („constrained dynamics effect") вследствие доотверждения (более полной полимеризации) матрицы и „встраивания“ в матричную сетку нанослоев ММТ. Последний эффект контролируется площадью межфазных слоев. Температура стеклования отвержденных образцов $T_{g}$ (DMA) равнялась $380-390^{\circ} \mathrm{C}$. В результате доотверждения она повышалась в случае индивидуальной матрицы до $446^{\circ} \mathrm{C}$ и до $460-570^{\circ} \mathrm{C}$ для нанокомпозитов. Показано возникновение резко выраженной динамической гетерогенности в переходе стеклования нанокомпозитов.

5. Наиболее существенное влияние воздушной среды, обусловленное началом термоокислительной деструкции нанокомпозитов, начинается с температур $\sim 500^{\circ} \mathrm{C}$. Введение 2\% ММТ частично ингибирует этот процесс: остаточная масса при $\sim 700^{\circ} \mathrm{C}$ возрастает от $7 \%$ для чистой матрицы до 45\% для нанокомпозита.

6. Высокотемпературная обработка и последующее испытание нанокомпозита в среде азота приводит к полному подавлению перехода стеклования, уникальному для полимеров сохранению постоянства величины модуля упругости $E^{\prime} \approx 3 \mathrm{GPa}$ в диапазоне температур от $20^{\circ}$ до $600^{\circ} \mathrm{C}$ и к сохранению целостности материала в бескислородной среде до $\sim 900^{\circ} \mathrm{C}$. Последнее объясняется сверхвысокой термостабильностью фталоцианиновых гетероциклов в инертной атмосфере.

7. Благодаря необычайно высокой термической стабильности и другим важным свойствам, исследованные нанокомпозиты имеют очевидную перспективу их применения в экстремальных температурных условиях в аэрокосмической технике, микроэлектронике и др.

\section{Благодарности}

TEM и EDXS эксперименты выполнялись с использованием оборудования Федерального ЦКП, поддержанного Минобрнауки России (Уникальный идентификатор проекта RFMEFI62117X0018). TGA эксперименты выполнялись с использованием оборудования ЦКП Института химии высокомолекулярных соединений НАНУ.

\section{Конфликт интересов}

Авторы заявляют, что у них нет конфликта интересов.

\section{Список литературы}

[1] Chemistry and Technology of Cyanate Ester Resins / Ed. I. Hamerton. Chapman and Hall, Glasgow (1994). 362 c.

[2] Thermostable Polycyanurates: Synthesis, Modification, Structure and Properties / Ed. A.M. Fainleib. Nova Science Publishers, N.Y. (2010). 362 c. 
[3] M. Derradji, J. Wang, W.B. Liu. Phthalonitrile resins and composites. Properties and applications. Elsevier, N.Y. (2018). $404 \mathrm{c}$.

[4] T.M. Keller, A. Va. Phthalonitrile resin from diphthalonitrile monomer and amine. 4,408,035, US Patent (1983).

[5] T.M. Keller, T. Price. J. Macromol. Sci. A 18, 931 (1982).

[6] T.M. Keller. J. Polymer Sci. A 26, 3199 (1988).

[7] Y. Lei, G. Hu, R. Zhao, H. Guo, X. Zhao. J. Phys. Chem. Solids 73, 1335 (2012).

[8] M. Derradji, N. Ramdani, T. Zhang, J. Wang, Z. Lin, M. Yang, X. Xu, W. Liu. Mater. Lett. 149, 81 (2015).

[9] M. Derradji, J. Wang, W.B. Liu. Mater. Lett. 182, 380 (2016).

[10] M. Derradji, N. Ramdani, L.-D. Gong, A. Henniche, W.B. Liu. Polymers Adv. Technol. 27, 882 (2016).

[11] X. Li, B. Yu, D. Zhang, J. Lei, Z. Nan. Polymers 9, 334, 1 (2017).

[12] V.A. Bershtein, A.M. Fainleib, P.N. Yakushev, D.A. Kirilenko, K.G. Gusakova, D.I. Markina, O.G. Melnychuk, V.A. Ryzhov. Polymer 165, 39 (2019).

[13] D.A. Kirilenko, A.T. Dideykin, A.E. Aleksenskiy, A.A. Sitnikova, S.G. Konnikov, A.Ya. Vul'. Micron 68, 23 (2015).

[14] E.P. Gannelis, R. Krishnamourt, E. Manias. Adv. Polymer Sci. 138, 108 (1999).

[15] V.A. Bershtein, P.N. Yakushev. Adv. Polymer Sci. 230, 73 (2010).

[16] V.A. Bershtein, A.M. Fainleib, L.M. Egorova, K.G, Gusakova, O.P. Grigoyeva, D.A. Kirilenko, S.G. Konnikov, V.A. Ryzhov, P.N. Yakushev, N. Lavrenyuk. Nanoscale Res. Lett. 10, 165, 1 (2015).

[17] V.A. Bershtein, A.M. Fainleib, D.A. Kirilenko, P.N. Yakushev, K.G. Gusakova, N. Lavrenyuk, V.A. Ryzhov. Polymer 103, 36 (2016).

[18] V.A. Bershtein, A.M. Fainleib, K.G. Gusakova, D.A. Kirilenko, P.N. Yakushev, L.M. Egorova, N. Lavrenyuk, V.A. Ryzhov. Eur. Polymer J. 85, 375 (2016).

[19] A. Leszczynska, J. Njuguna, K. Pielichowski, J.R. Banerjee. Thermochim. Acta 454, 1 (2007).

Редактор Т.Н. Василевская 